\title{
Physio-Chemical Investigation and Natural Bond Orbital Analysis of the Most Actives Ingredient of Fennel Plant
}

\author{
MANSOUREH PISHEHABADI and ALI REZA ILKHANI* \\ Department of Chemistry, Yazd Branch, Islamic Azad University, Yazd, Iran. \\ *Corresponding author E-mail: ilkhaniali@iauyazd.ac.ir
}

http://dx.doi.org/10.13005/ojc/320519

(Received: September 26, 2016; Accepted: October 15, 2016)

\begin{abstract}
In this study, physio-chemical properties of effective compounds of fennel plant were investigated through using computational chemistry. To do this, trans-anethole, estragole, 3'hydroxyanethole and 4- methoxycinnamyl alcohol compounds that the most active ingredient combinations make up the fennel plant have been carried out at three different levels of HF, BLYP and B3LYP theories using 6-31G* $6-311 \mathrm{G}^{*}, 6-311 \mathrm{G}^{* *}, 6-311+\mathrm{G}$ and $6-311++\mathrm{G}$ basis sets. Additionally, $\mathrm{ab}$ initio calculation in the gas phase have been studied and physio-chemical parameters including Gibbs free energy, thermal energy, enthalpy, entropy, and thermal capacity in constant volume $\left(C_{v}\right)$ of these compounds have been computed as well as Gibbs free energy in polar solvents such as ethanol and methanol and water. Based on these obtained data the structural stabilities of these flavorful compounds have been discussed. However, in these herbal effective compounds presented here the natural bond orbital (NBO) analysis has been performed which seemed quite informative to show some important atomic and structural features. The result lead to the issue that all those compounds in polar solvents, particularly alcoholic solvents solved and the compounds can be used sufficiently to extract the active ingredients of herb fennel.
\end{abstract}

Keywords: Active ingredient of fennel plant, Ab initio calculation, Physio-chemical properties, natural bond orbital.

\section{INTRODUCTION}

Foeniculum vulgare commonly known as fennel is a biennial medicinal and aromatic plant belonging to the family Apiaceae (Umbelliferaceae) ${ }^{1}$. Based on many phyto-constituents in fennel plant such as trans-anethole, and estragole compounds, it widely employed as important medicinal herbal to treat respiratory and gastrointestinal disorders and those phyto-compounds are founded in different parts of the plant including the oil, the dried ripe fruit and the seeds ${ }^{2}$.

Fennel seeds are used not only as a famous spices to flavored meat, chicken and seafood, but also as flavoring agents for desserts such as ice cream, or beverages. Several pharmacological experiments has identified fennel as a valuable medicinal plant with potential for multipurpose uses and also as a source for preparing raw materials of pharmaceutical 
industry, especially steroidal hormones ${ }^{3}$. As examples fennel is rich in phytoestrogens and is used for estrogen deficiency disorders and estrogens affect anxiety through neurochemical systems such as GABA-A receptors ${ }^{4}$ or the positive impact of fennel for vaginal conditions occurring among postmenopausal women ${ }^{5}$.

In the works cited above important features of the fennel and its application as flavorful herb with culinary and medicinal uses were revealed and investigated, less attention was paid to the structural stabilities of the compounds and solvent effect. Therefore physio-chemical parameters including Gibbs free energy, thermal energy, enthalpy, entropy, and thermal capacity in constant volume $\left(\mathrm{C}_{\mathrm{v}}\right)$ of these compounds have been computed in different level of theoretical calculation and several basis sets. Chemical structures of Trans-anethole, Estragole, 3'Hydroxyanethole, and 4- Methoxycinnamyl alcohol as the most effectives ingredient of the fennel plant are performed in Figure 1.

\section{Computational details}

Whole quantum computation that have been performed in present research using by Gaussian 98 program ${ }^{6}$. Full geometry optimizations of the most actives ingredient of fennel plant have been carried out employing Hartree-Fock (HF) 7,8 and density Functional theory (BLYP and B3LYP) ${ }^{9,10}$ with 6-31G*, $6-311 G^{*}, 6-311 G^{* *}, 6-311+G$, and $6-311++G$ basis sets ${ }^{11}$.

For further investigation of the substituent effects, the thermochemical parameters including thermal energies, and entropies, Gibbs free energies and entropies of under consideration compounds of those four above active compounds of fennel plant have been performed to find the most stable candidate for fennel as steroidal hormones which full fills their structural stability.

To evaluate the ab initio and DFT calculation methods dependence of physio-chemical properties, such as Gibbs free energy, thermal energy, enthalpy, entropy, and $C_{v}$ have been carried out at different basis sets. The graphs of those thermochemical properties at different basis sets has been plotted and analyzed. Moreover, to evaluate the applicability of using different solvent especially for polar solvent effect on these physio-chemical parameters, the relative calculated Gibbs free energies values in water, methanol and ethanol has been computed through comparing HF, BLYP and B3LYP methods
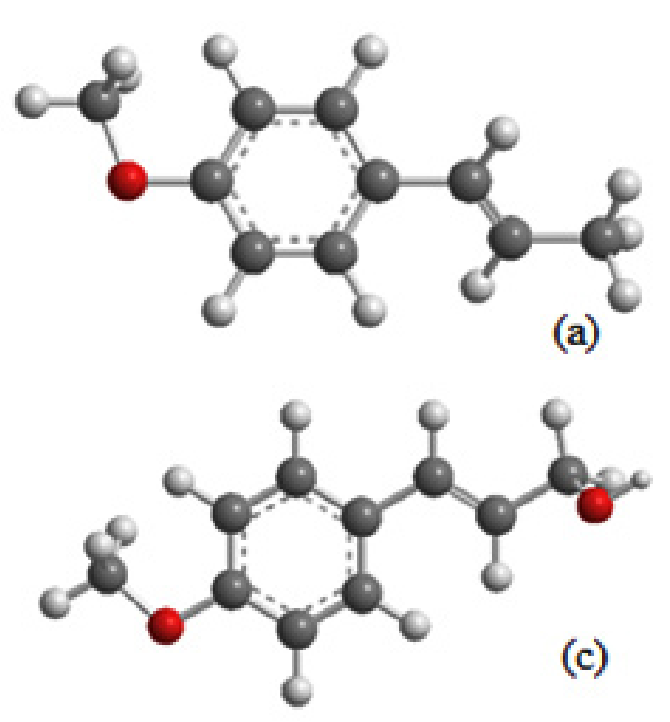
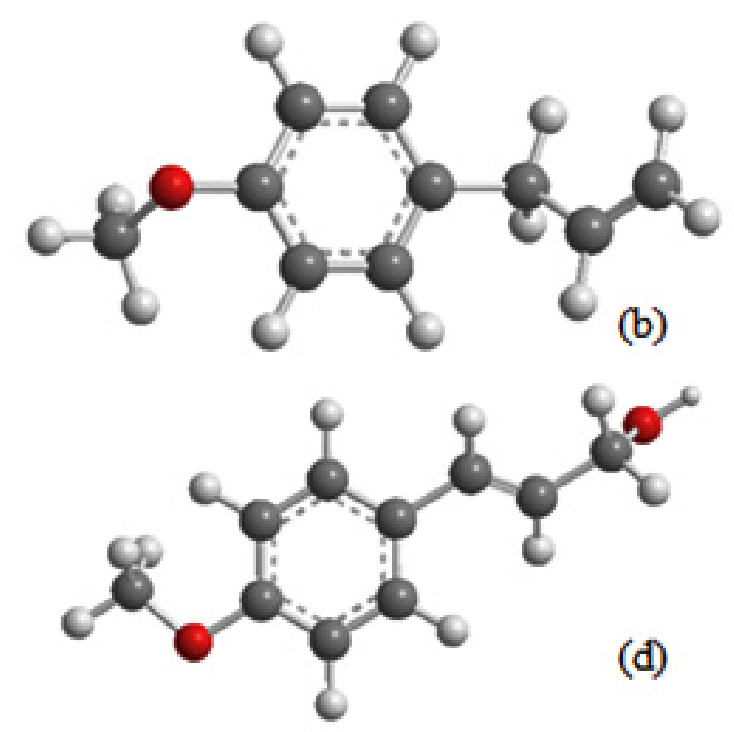

Fig. 1: Chemical structure of the most effectives ingredient of the fennel plant Trans-anethole (a) Estragole (b), 3'- Hydroxyanethole (c), and

4- Methoxycinnamyl alcohol (d) (atomic representations: $\mathrm{O}=$ red, $\mathrm{C}=$ gray, $\mathrm{H}=$ white) 
(1)

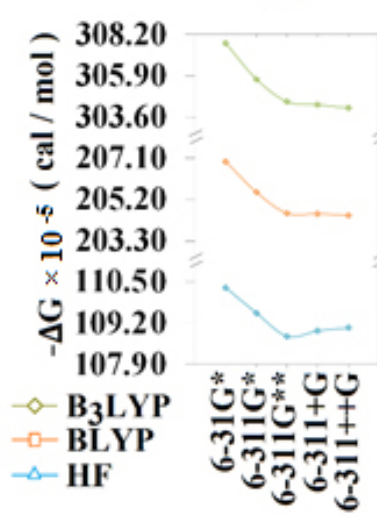

(1)

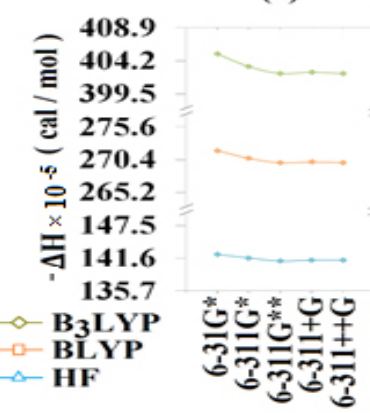

(1)

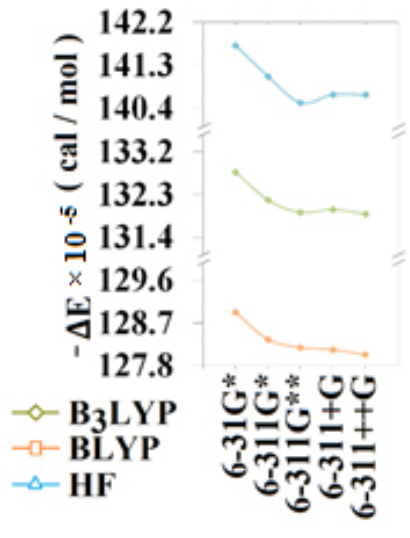

(2)

307.97
304.98
301.99
209.30
206.31
203.32
111.44
109.45
107.46

408.0
405.0
402.0
272.0
270.0
268.0
143.0
142.0
141.0

(2)

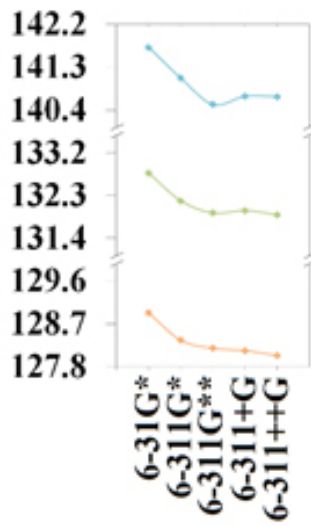

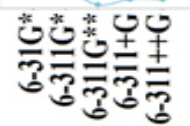

(3)

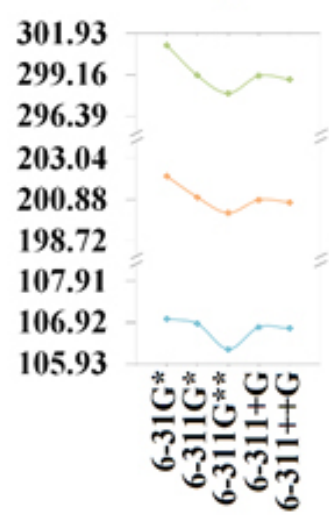

(3)

394.2

391.6

389.1

266.2

263.6

261.1

139.5

136.6

133.6

(3)

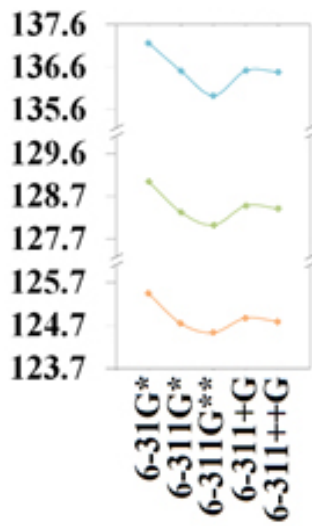

(4)

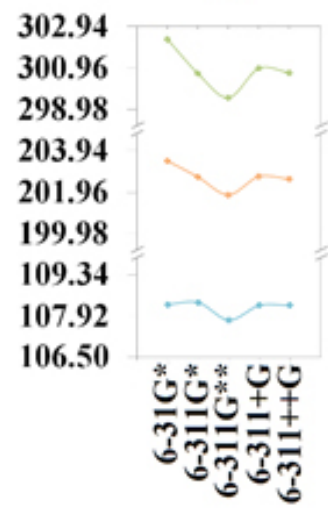

(4)

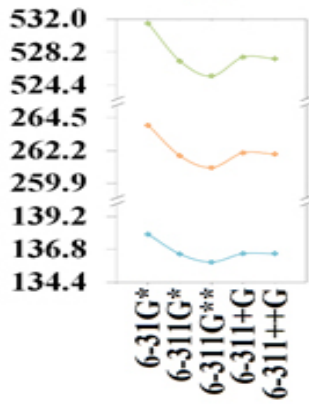

(4)

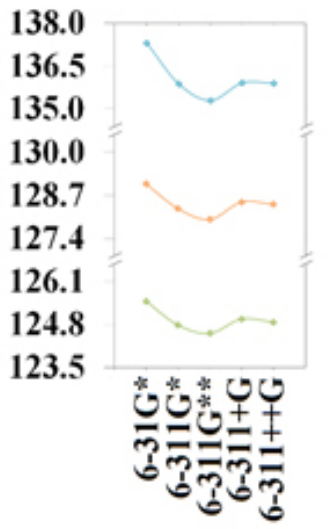

Fig. 2: Physio-chemical properties of Trans-anethole (1), Estragole (2), 3'- Hydroxyanethole (3) and 4- Methoxycinnamyl alcohol (4) compounds obtained at different theoretical levels and basis sets 
(1)

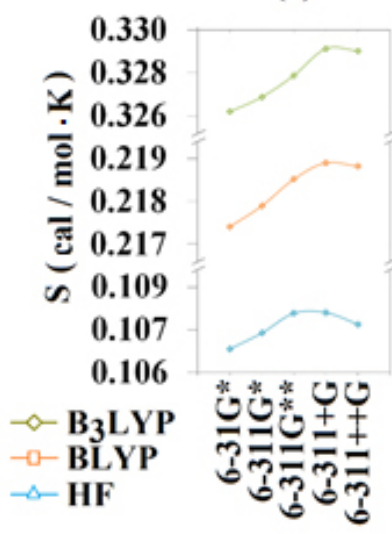

(1)
(2)

0.330
0.328
0.326
0.220
0.218
0.216
0.109
0.107
0.105

0.105

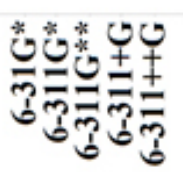

(2)

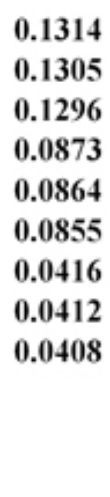

(3)

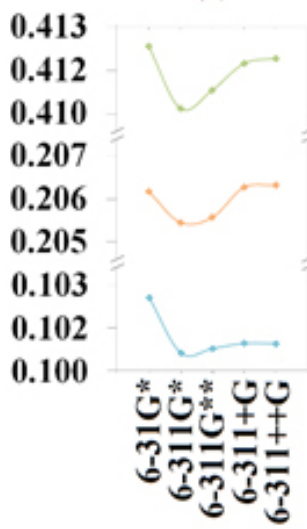

(3)

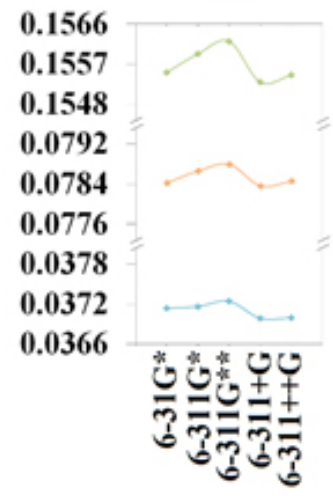

(4)

0.110
0.100
0.090
0.105
0.104
0.103
0.104
0.103
0.102

0.110

0.100

0.090

0.105

0.104

0.103

0.104

0.102

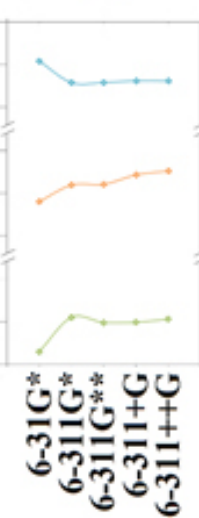

(4)

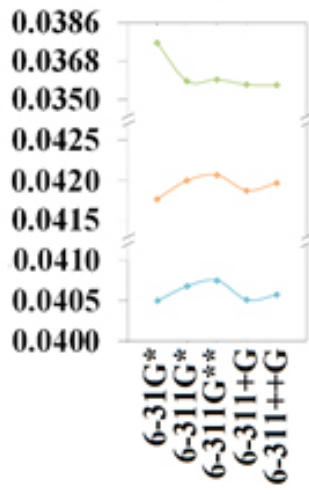

Fig. 3: Entropy and Cv of Trans-anethole (1), Estragole (2), 3'- Hydroxyanethole (3), and 4Methoxycinnamyl alcohol (4) compounds versus basis set changes in different theoretical computational levels<smiles>C/C=C/c1ccc(OC)cc1</smiles>

Trans-anethole<smiles>COC=Cc1ccc(OC)cc1</smiles>

3'-Hydroxyanethole<smiles>C=CCCc1ccc(OC)cc1</smiles>

Estragole<smiles>CO/C=C/c1ccc(OC)cc1</smiles>

4- Methoxycinnamyl alcohol

Fig. 4: Two dimensional structures of Trans-anethole, Estragole, 3'- Hydroxyanethole, and 4- Methoxycinnamyl alcohol 
0000000000000000000000000000000

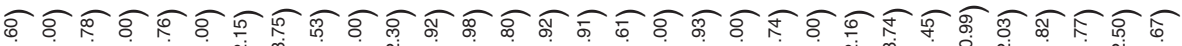

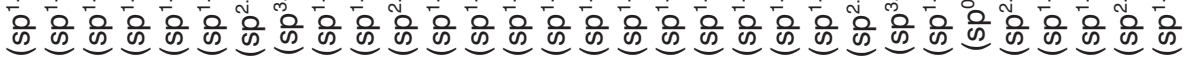

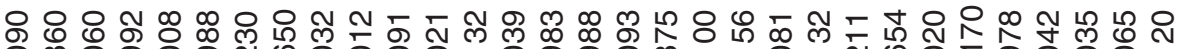

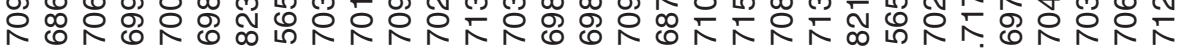

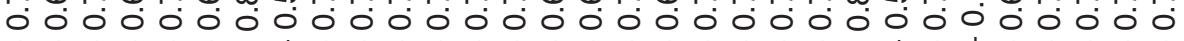

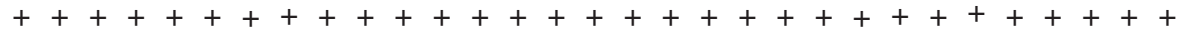
0000000000000000000000000000000

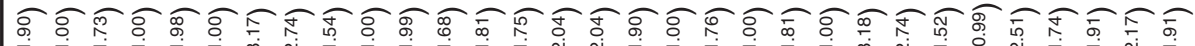

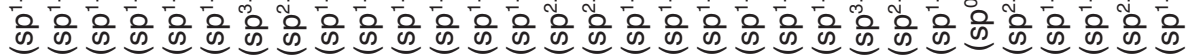

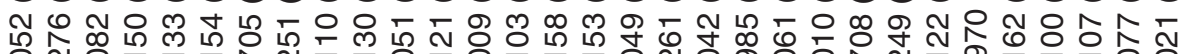

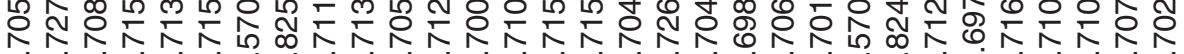

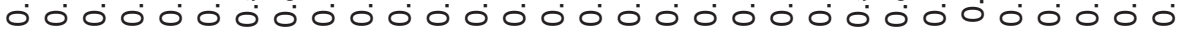

0000000000000000000000000000000

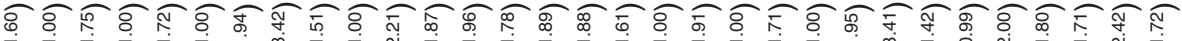

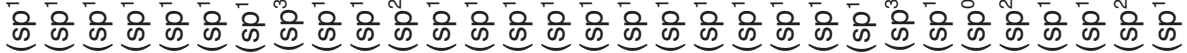
N N

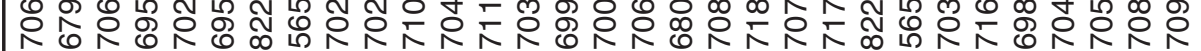

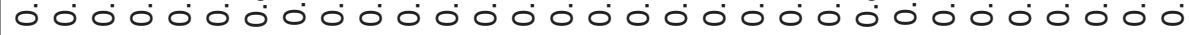

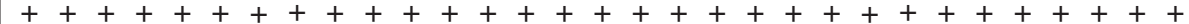
0000000000000000000000000000000

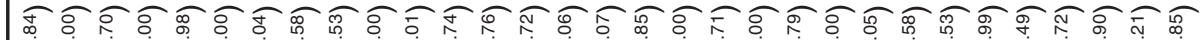

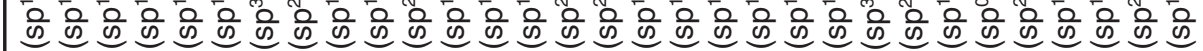

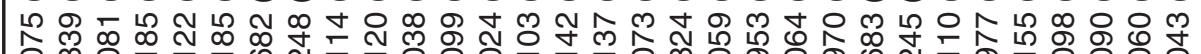

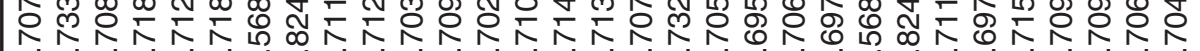

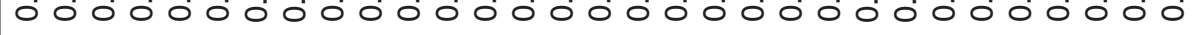

0000000000000000000000000000000

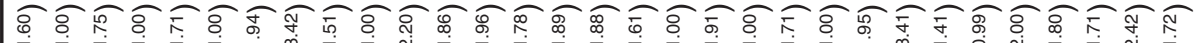

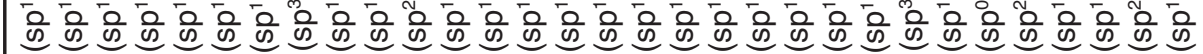

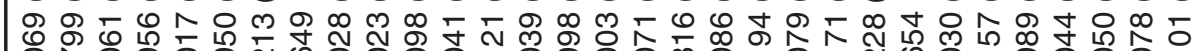

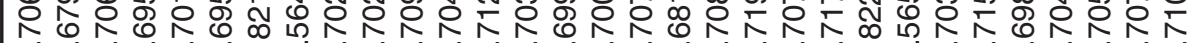

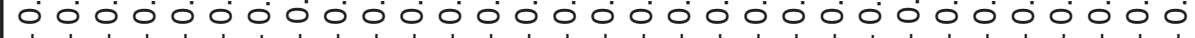
$+++++++++++++++++++++++++++++++++$

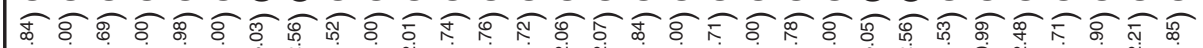

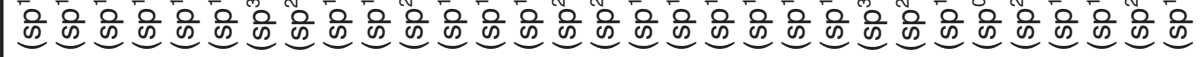
끼요

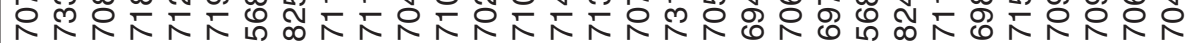

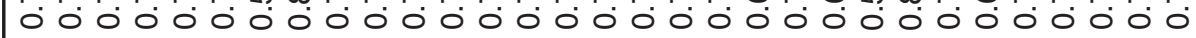

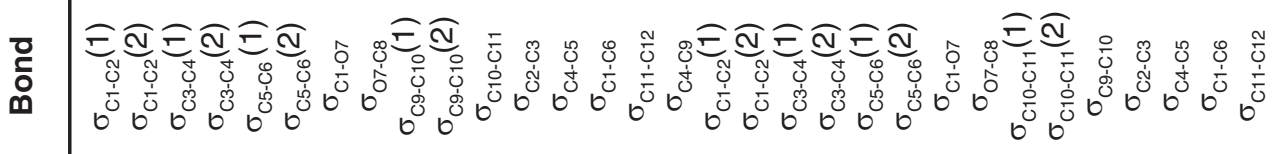

을

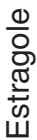




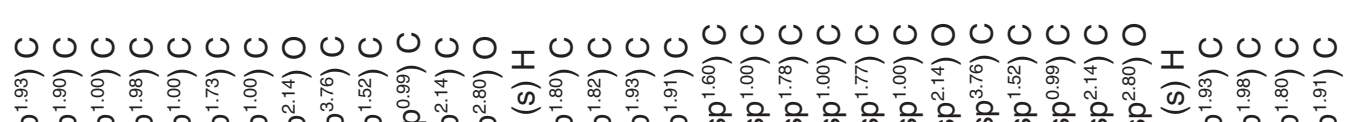

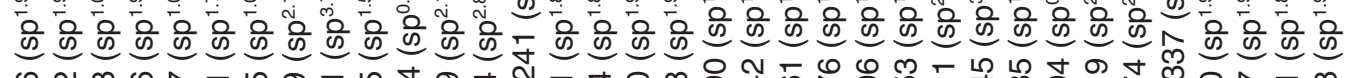

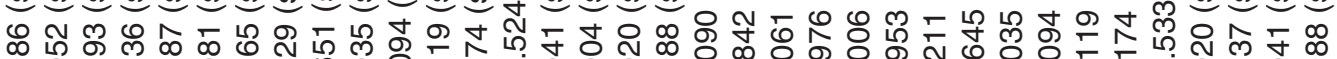

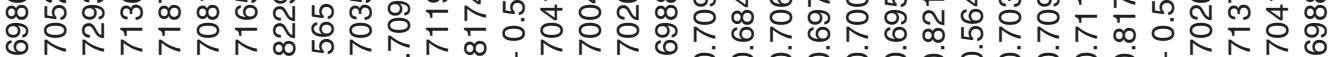

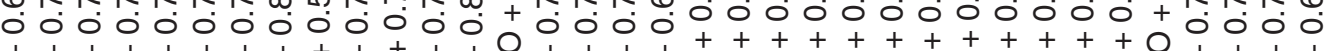
$+++++++++++++0+++++++++++++++++0+++t$ 0000000000000 I0000000000000000

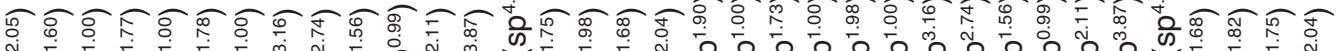

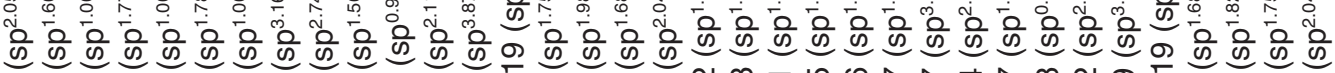

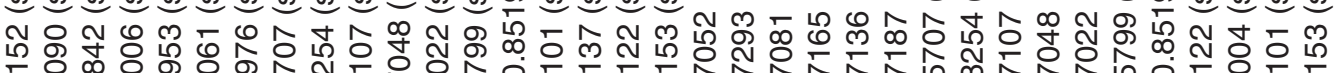

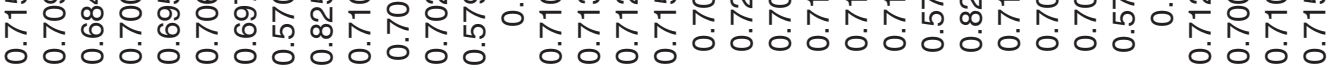

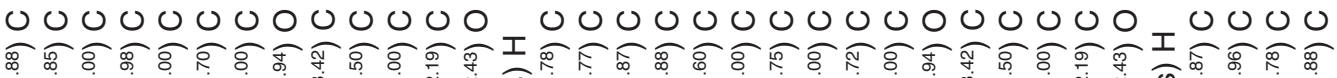

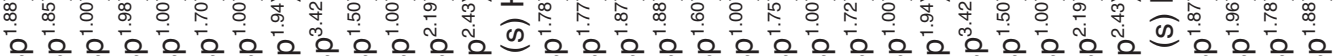

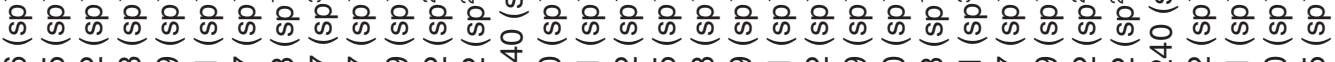

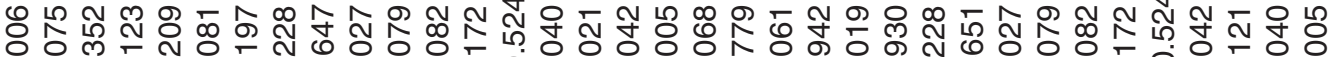

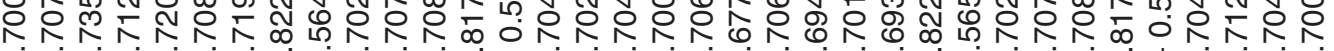
- $000000000000+0000000000000000+0000$

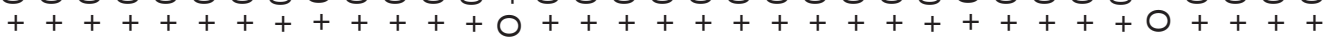
0000000000000 б0000000000000000囱0000

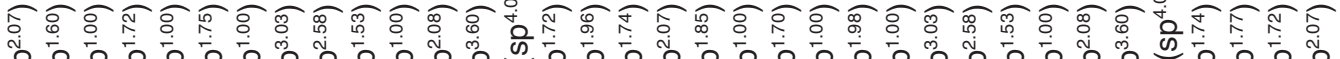
क्ष 0

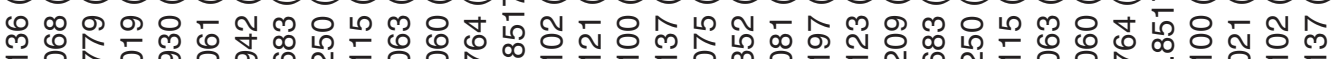

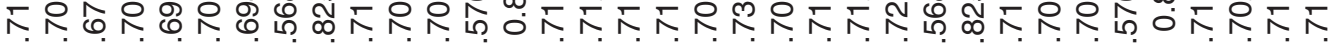
000000000000000000000000000000000000

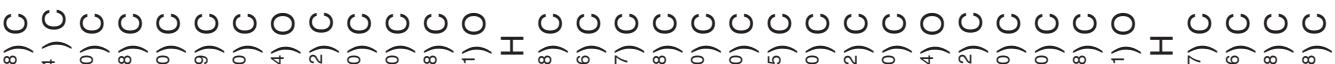

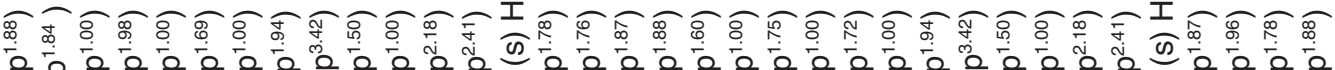

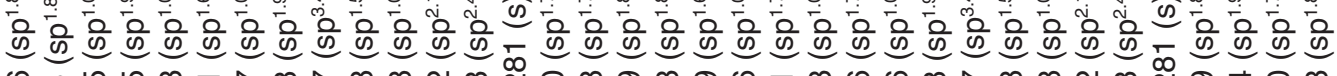
\&

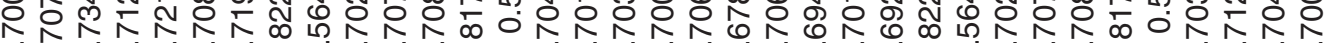

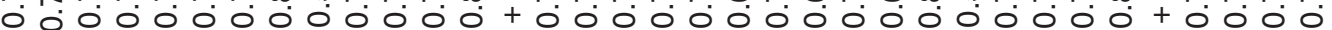

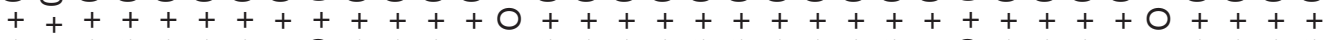
0000000000000

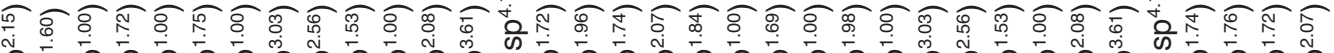

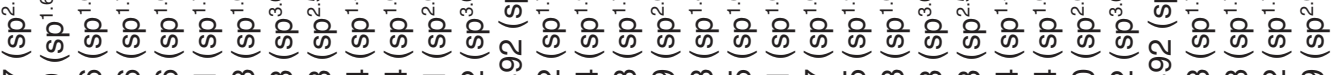

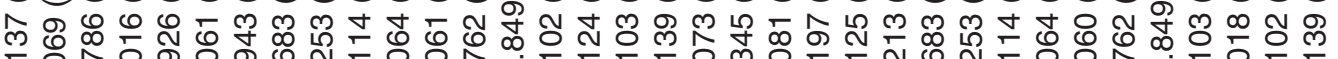

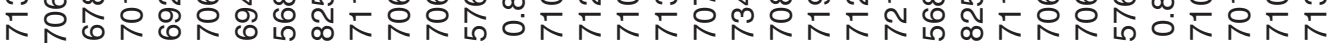

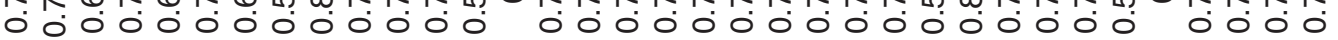

ช

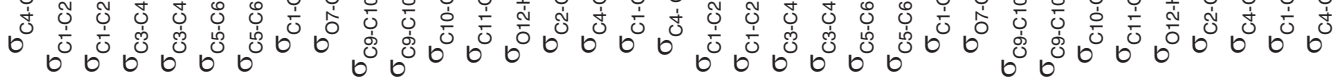

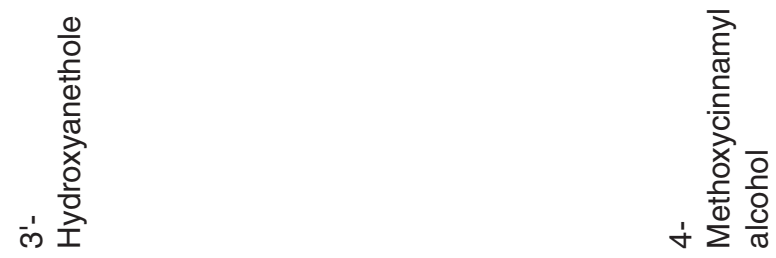


for selected $6-311 G^{*}, 6-311 G^{* *}$, and $6-311++G$ basis sets. Also, the Gibbs free energy (that is called solvation Gibbs free energy) results versus polarity of solvent have been analyzed. Finally, NBO analysis has been carried out to explore the distribution of electrons into atomic and molecular orbitals and thereby derived molecular bonds are then based on the percentage of $\mathrm{P}$ orbitals of some nuclei for different bonds of considered fennel compounds have been investigated and analyzed using DFT approach. Also, the ratios of core/charge and valence/charge of some nuclei have been compared and analyzed.

\section{RESULTS AND DISCUSSION}

Our investigation have been based on quantum chemical calculations to understanding solvent effect and identification of active site of the considered compounds to make shorten the long way from clinical trials to the final approval of the herbal fennel for estrogen deficiency disorders and estrogens affect anxiety.

\section{Analysis of physio-chemical properties}

The graph of calculated Gibbs free energies, enthalpies, thermal energies concerning to Trans-anethole, Estragole, 3'- Hydroxyanethole and 4- Methoxycinnamyl alcohol compounds versus basis set changes in different theoretical computational levels have been summarized in Figure 2.

From the reported physio-chemical properties in Figure 2 we can see that Trans-anethole and Estragole have highest negative Gibbs free energies and enthalpies and thermal energies of these four effective compounds of fennel plant at different HF, BLYP and B3LYP levels (except calculated enthalpies of 4- Methoxycinnamyl alcohol). It has also the most structural stability amongst other consideration fennel compounds. So, as a whole, the order of stability obtained is thus:

Trans-anethole $\approx$ Estragole $>4$ - Methoxycinnamyl alcohol > 3'- Hydroxyanethole

Additionally, the graphs of entropy, and $\mathrm{Cv}$ of four compounds as effective compounds of fennel plant in HF, BLYP, and B3LYP for several basis sets such as $6-31 G^{*}, 6-311 G^{*}, 6-311 G^{* *}, 6-311+G$, and $6-311++\mathrm{G}$ has been displayed in Figure 3 .

From Figure 3 is appeared that calculated entropy and $C_{v}$ values belong to Trans-anethole, and Estragole almost are similar in different level of calculation methods and basis sets although their values are maximum and minimum for $3^{\prime}$ Hydroxyanethole and 4- Methoxycinnamyl alcohol

Table 2: Solvation Gibbs free energy of four effective compounds of fennel plant in ethanol, methanol and water obtained at different solvents at different theoretical levels

\begin{tabular}{|c|c|c|c|c|c|c|c|c|c|c|}
\hline \multirow[t]{3}{*}{ Compound } & \multirow{3}{*}{$\begin{array}{l}\text { Basis set } \\
\text { Solvent }\end{array}$} & \multicolumn{6}{|c|}{$-\Delta \mathbf{G} \times 10^{-5}$ solvation $(\mathrm{Cal} / \mathrm{mol})$} & \multirow{2}{*}{\multicolumn{3}{|c|}{$6-311++G$}} \\
\hline & & \multicolumn{3}{|c|}{$6-311 G^{*}$} & \multicolumn{3}{|c|}{$6-311 G^{\star \star}$} & & & \\
\hline & & HF & BLYP & B3LYP & HF & BLYP & B3LYP & HF & BLYP & B3LYP \\
\hline \multirow{3}{*}{$\begin{array}{l}\text { Trans- } \\
\text { anethole }\end{array}$} & Ethanol & 3.27 & 3.64 & 3.91 & 3.10 & 3.55 & 3.79 & 4.42 & 5.46 & 4.80 \\
\hline & Methanol & 6.30 & 6.71 & 6.98 & 6.12 & 6.62 & 6.86 & 7.52 & 8.56 & 7.90 \\
\hline & Water & 3.03 & 3.43 & 3.76 & 2.84 & 3.33 & 3.64 & 4.27 & 4.69 & 5.40 \\
\hline \multirow[t]{3}{*}{ Estragole } & Ethanol & 2.82 & 2.84 & 3.00 & 2.38 & 2.46 & 2.52 & 3.95 & 4.58 & 4.96 \\
\hline & Methanol & 5.78 & 5.80 & 5.98 & 5.36 & 5.46 & 5.48 & 6.93 & 7.60 & 8.01 \\
\hline & Water & 2.33 & 2.38 & 2.58 & 1.93 & 2.00 & 2.03 & 3.50 & 4.20 & 4.71 \\
\hline $3^{\prime}-$ & Ethanol & 10.76 & 10.85 & 11.40 & 9.44 & 9.84 & 10.03 & 12.12 & 12.43 & 12.64 \\
\hline \multirow[t]{2}{*}{ Hydroxylanethole } & Methanol & 14.10 & 14.23 & 14.80 & 12.80 & 13.17 & 13.40 & 15.50 & 15.87 & 16.08 \\
\hline & Water & 11.00 & 11.12 & 11.76 & 9.63 & 10.05 & 10.31 & 12.43 & 12.84 & 13.06 \\
\hline 4- & Ethanol & 10.08 & 10.51 & 10.62 & 8.85 & 9.31 & 9.66 & 12.04 & 12.13 & 12.57 \\
\hline \multirow{2}{*}{$\begin{array}{l}\text { Methoxycinnamyl } \\
\text { alcohol }\end{array}$} & Methanol & 13.44 & 13.96 & 13.97 & 12.19 & 12.66 & 12.98 & 15.42 & 15.54 & 16.02 \\
\hline & Water & 10.28 & 10.68 & 10.89 & 8.99 & 9.56 & 9.66 & 12.35 & 12.49 & 13.03 \\
\hline
\end{tabular}


compounds, respectively. We also can see that entropies of 4- Methoxycinnamyl alcohol in HF methods are higher than in BLYP and B3LYP which is opposite results in comparsion other physiochemical parameters that showed in Figures 2 and 3.

\section{NBO analysis}

The concept of natural atomic orbital (NAO) and NBO analysis which is useful for distributing electrons into atomic and molecular orbitals used for the one-electron density matrix for defining the shape of the atomic orbitals in the molecular environment and then derive molecular bonds from electron density between atoms ${ }^{12}$. Two dimensional structures of Trans-anethole, Estragole, 3'- Hydroxyanethole, and 4- Methoxycinnamyl alcohol as the most actives ingredient of fennel plant has been performed in Figure 4.

The results of NBO analysis using B3LYP method with three large basis sets, that are 6-311G*, $6-311 \mathrm{G}^{\star *}$, and $6-311++\mathrm{G}$ have been reported in Table 1. We have observed the highest percentage of $\mathrm{P}$ orbitals were belonged to oxygen atoms that are in $\mathrm{C} 1-\mathrm{O} 7$ and $\mathrm{O} 7-\mathrm{C} 8$ bonds of all under consideration compounds and $\mathrm{C} 11-\mathrm{O} 12$ and $\mathrm{O} 12-\mathrm{H} 13$ of $3^{\prime}-$ Hydroxyanethole, and 4- Methoxycinnamyl alcohol compounds. It is important to notice that the highest $\mathrm{P}$ orbital percentage has been identified for $\mathrm{C}-\mathrm{O}$ and $\mathrm{O}-\mathrm{H}$ bonds in all four compounds. Interestingly, using all consider quantum chemical methods for these four effective compounds of the fennel plant this maximum value of $P$ orbital has been obtained with the large basis set, that is, $6-311++G^{* *}$ which reflected its high accuracy amongst considered basis sets.

\section{Solvent effect}

In continuation the calculation results, Gibbs free energy of Trans-anethole, Estragole, 3'- Hydroxyanethole, and 4- Methoxycinnamyl alcohol herbals in three popular polar solvents such as water, methanol and ethanol have been calculated in B3LYP method with large basis sets, $6-311 \mathrm{G}^{*}, 6-311 \mathrm{G}^{* *}$, and $6-311++\mathrm{G}$, as same as for NBO calculation and the results are summarized in Table 2.
If we compare the results of solvation Gibbs free energy in Table 2, it is appeared that using B3LYP/6-311++G calculation method and basis set lead us to more sufficient results than does the other employed methods and basis sets. Additionally, when we changing methods from HF to BLYP as well as B3LYP, solvation Gibbs free energy in all considered compounds rise to the most negative value and stability of molecules in solution was increased. Interestingly, highest solvation Gibbs free energy is belong to methanol in all compounds. Furthermore, solvation Gibbs free energy value in 3'- Hydroxyl anethole, and 4- Methoxycinnamyl alcohol significantly are higher than Trans-anethole, and Estragole which are belonged to $\mathrm{O}-\mathrm{H}$ group their chemical structures.

\section{CONCLUSIONS}

The procedures discussed in this study place much emphasis on the importance of stability structure calculations of physio-chemical parameters and solvent effect as well as NBO analysis of Transanethole, Estragole, 3'- Hydroxyanethole, and 4- Methoxycinnamyl alcohol as the most actives ingredient of fennel plant. To illustrate the impact of electron correlation and basis set effects on the predicted thermochemical and NBO parameters of considered herbals, we have employed there different theoretical methods including Hartee-Fock (HF), and density functional theory (BLYP and B3LYP) and methods with $6-31 G^{*}, 6-311 G^{*}, 6-311 G^{* *}, 6-311+G$ and $6-311++G$ basis sets to study the substituent effects of the herbals as well as bioactivity caused by their structural stabilities and corresponding physio-chemical parameters. It has been found out that DFT calculations reproduce well the mentioned parameters. The larger 6-311++G basis set is much more recommended, because it gives slightly better results and then does the other employed cases. The activity and stability as well as solvent effect of the herbals are strongly affected under physio-chemical properties at the specific temperature. So, out of the many desired drug physico-chemical parameters that is relate to the structural stability and then their optimal bioactivity, we have considered here a subset of physio-chemical properties in gas phase and some polar solvents that have to be fulfilled in many biological systems. 


\section{REFERENCES}

1. Manzoor. R.; Bilal. D.; Shahnawaz S.; Bilai B.; Mushtaq Q. Arabian J. Chem. 2012, 11, 1-10

2. Javadi S.; Ilkhnipour M.; Heidari R.; Nejati V.; J. Medwell Publishing. 2008, 3, 47-49

3. Staffi G.; Malik C. P.; Amandeep H.; Bhati K. H.; Botany, Int. J. Life Sci. . 2013, 2,128-139

4. Pourabbas S.; Kesmati M.; Rasekh A.; Physiology and Pharmacology 2011, 15, 134-143

5. Yaralizadeh M.; Najar S.; Namjoyan F.; Saki A.; Maturitas Eur. Menopaus J. 2016, 84 ,75-80

6. Frisch M. J.; Trucks G. W.; Schlegel H. B.; Scuseria G. E.; Robb M. A.; Cheeseman J. R.; Zakrzewski V. G.; Montgomery J. A.; Stratmann R. E.; Burant J. C.; Dapprich S.; Millam J. M.; Daniels A. D.; Kudin K. N.; Strain M. C.; Farkas O.; Tomasi J.; Barone V.; Cossi M.; Cammi R.; Mennucci B.; Pomelli C.; Adamo C.; Clifford S.; Ochterski J.; Petersson G. A.; Ayala P. Y.; Cui Q.; Morokuma K.; Malick D. K.; Rabuck A. D.; Raghavachari
K.; Raghavachari J. B.; Cioslowski J.; Ortiz J. V.; Baboul A. G.; Stefanov B. B.; Liu G.; Liashenko A.; Piskorz P.; Komaromi I.; Gomperts R.; Martin R. L.; Fox D. J.; Keith T.; Laham M. A.; Peng C. Y.; Nanayakkara A.; Gonzalez C.; Challacombe M.; Gill P. M. W.; Johnson B.; Chen W.; Wong M.W.; Andres J. L.; Gonzalez C.; Gordon M. H.; Replogle E. S.; Pople J. A.; 1998 Gaussian, Inc., Pittsburgh PA Gaussian 98 Revision A.7.

7. Roothan C. C. J.; Rev. Mod. Phys. 1951, 23, 69-78

8. Pople J. A.; Nesbet R. K.; J. Chem. Phys.1954, 22, 571.

9. Becke A. D. J.; Chem. Phys. 1993, 98, 4648.

10. Lee C.; Yang W.; Parr R.G.; Phys. Rev. B 1998, 37, 785-793

11. Frisch M.J.; Pople J.A.; Del Bene J. E.; J. Phys. Chem. 1985, 89, 3664-3669

12. Jensen F.; John Wiley \& Sons Ltd. 2007, Second Edition 